\title{
CORRELATES OF MOTHERS' USE OF MEDICATIONS FOR THEIR CHILDREN
}

\author{
Lois A. Maiman', Marshall H. Becker ${ }^{2}$ and Anne W. Katlic \\ 'Department of Pediatrics. School of Medicine and Dentistry, University of Rochester, Rochester. \\ NY 14642 and ${ }^{2}$ Department of Health Behavior and Health Education, School of Public Health. \\ University of Michigan, Ann Arbor, Mich., U.S.A.
}

\begin{abstract}
This study examines the extent, determinants and quality of mothers' independent use of medications for treating their children's symptoms. Data on mother-initiated medication behavior (MIMB) were obtained from a stratified systematic random sample of 500 mothers of children presenting for a well child visit at two pediatric ambulatory care sites. Six expert pediatric judges each rated every reported medication use $(N=3908)$ along three dimensions (usefulness, correctness and harmfulness or helpfulness) and also evaluated the overall appropriateness of each mother's MIMB. Results indicate that: (1) mothers keep available and use for children a considerable variety of different medications and medical applicances: (2) a positive linear relationship exists between mothers' socioeconomic status (SES) and degree of MIMB; (3) mothers' attitudes toward medications and toward their children's health are associated with the number of categories of medications and applicances they possess and use; (4) the combination of SES and attitudinal characteristics accounts for substantial portions of the variance in MIMB; and (5) judges" ratings show only minimal-level support of MIMB (extending to mothers in all SES groups) and are linearly related to SES $(P<0.001)$. These findings emphasize the need for health care providers to review MIMB, and to provide advice concerning use and misuse of mother-initiated treatments.
\end{abstract}

\section{INTRODUCTION}

In recent years the impressive magnitude of consumer expenditures in the United States for nonprescription medication (NPM) (estimated at 9 billion dollars in 1980) [1] and findings of approx. 2 to 3 times as much use of nonprescribed as prescribed medicine in Britain and the United States [2,3] have generated considerable interest in how these products are used. Although previous research has provided some data about rates of usage and associated individual characteristics. only two studies have attempted multivariate analyses of the combined and relative importance of proposed explanatory variables, and these studies have focused on adults.

The existing multivariate studies possess conceptual limitations in their definitions of NPM use. In examining reported use of medications not prescribed by a physician, including NPMs and leftover prescription medications, Bush and Osterweis [4] selected a recall period (the 2 days prior to the interview) that is only sensitive to use for discrete incidents by the subgroup of the study population expected to engage in such behavior during that time $(36 \%$ of subjects) and neglects the extent of general patterns of self-management of ailments in the total population. In contrast. Johnson et al. [5] elicited

Supported by Grants 5 R01 HD15357 and 1 K04 HD00538 from the National Institute of Child Health and Human Development to Dr Maiman.

Address correspondence to: Lois A. Maiman, Ph.D.. Associate Professor. Department of Pediatrics, School of Medicine and Dentistry. University of Rochester, Rochester. NY 14642. U.S.A. reports of self-initiated medication use without a discretionary cut-off point; study subjects were divided as to whether or not they were 'ever users' or 'nonusers' of NMP, and 'users' were subdivided into three frequency categories ('very often', 'occasionally' and 'not very often'). This approach yields a higher utilization rate $(90 \%$ of subjects), but selfcategorization of the frequency of such behavior is likely to be sensitive to variations in individual perceptions of qualitative frequency of use (in contrast to more standardized quantitative selfassessment techniques).

Some surveys, two conducted in Britain $[2,6]$ and one in Monroe County, N.Y. [7], have concentrated on parental use of NPMs, and findings indicate that parents frequently diagnose and initiate treatment for ailments in their children. The veryconsiderable proportions of children receiving NPMs increases with the recall interval employed, from $22 \%$ of children during a 24-hour period [7], to $48 \%$ over 2 weeks [2], to $66 \%$ across 4 weeks [6]. When the extent of parent-initiated treatment is measured by the number of different 'types' of medications (e.g. vitamins, cold remedies, fever remedies) kept in the home by mothers for use when their child becomes ill, two-thirds of the mothers possessed 4 to 8 different types of medications [8]. Another study examined the responses of parents to management of hypothetical episodes of fever or nasal congestion in their children [9], and found that $79 \%$ of parents would medicate their children for 'fever' without first consulting a health professional (the rate obtained for "nasal congestion' was $54 \%$ ).

Other evidence from the United States and Britain suggests that parental administration of NPM is not 
related to the child's sex $[6$, p. $66 ; 10]$ or age $[6$, p. 66], but shows that children of better-educated, higher socioeconomic status (SES) mothers $[6$, pp. 68-69;8, pp. 143-146] and from smaller families [6, p. 68] receive more NPMs. Certain health attitudes held by mothers, perceiving their families as more frequently troubled by sickness $[6$, p. $70 ; 8$, p. 146] and expressing more faith in the value of over-the-counter (OTC) medications for managing their children's (and their own) illnesses [8, pp. 146-147], are associated with being more likely to employ self-initiated therapies for their children.

Beyond the confirmation of mother-initiated medication behavior (MIMB) lies the issue of qualitative assessment: are the therapies undertaken for these children helpful, benign or harmful-and is the quality of MIMB systematically related to potential explanatory variables (e.g. mothers' attitudes or sociodemographic factors)? Information available from the United States and Britain for adults revcals that consumers ignore the label warnings on NPMs, exceed the correct dosage, and over-extend recommended periods for administration without seeing a physician if symptoms persist [11-13]. Although many anecdotes exist from pediatric medical settings about unusual remedies employed by parents and related untoward outcomes, these basic assessment issues have not previously been subjected to empirical investigation.

The present study has three major objectives: (1) to describe the extent of mother-initiated medication behavior (MIMB) for children; (2) to better understand MIMB by exploring, singly and in combination, its associations with mothers' sociodemographic characteristics, and with mothers' attitudes and beliefs regarding their children's health and vulnerability to illness, the effectiveness and benefits of over-the-counter (OTC) medications, and their propensity to use such medications; and (3) to evaluate the quality of MIMB.

\section{METHODS}

\section{Sample}

Two study sites were chosen to assure variation in SES: a pediatric ambulatory care clinic at a teaching hospital and a large private pediatric group practice (both located in Rochester, N.Y.). From the estimated total volume of well child visits per month at each site, sampling fractions were generated to permit stratification and selection of children with probabilities proportionate to the number of children in each of 3 age strata. Over a 9-month period, a stratified systematic random sample of 250 mothers of children (2-12 years of age) presenting for a well child visit was obtained at each site (total $N=500$ ) The number of children sampled in each age stratum was: $165(33 \%)$ in the group $2-5$ years of age: 169 $(34 \%) 6-9$ years of age; and $166(33 \%)$ aged $10-12$.

Five mothers declined to participate and 7 interviews were incomplete, necessitating an oversampling of 12 to achieve $N$ s of 250 per site. A 30-minute structured interview, based on a pilot study [8] and further revised following a pretest for the present study, elicited the mother's reports of prior NPM use (including OTCs and leftover pre- scription medications) for the child scheduled for that visit (the "index child") and her beliefs and concerns related to the child's health, both general and specific to medication. Information concerning the mother's and child's sociodemographic characteristics was also obtained.

Mothers whose children had a current health problem were not included, since the existence of such a condition and its concomitant treatment might bias reports of usual MIMB and of relevant health attitudes. The age range for children was established as 2-12 years because: (1) mothers of very young children may have less frequent opportunity to treat illness; (2) mothers may be less willing to risk making their own decisions about medication treatment for very young children; and (3) there was concern that children over 12 years of age might be active participants in decisions about their treatment, thus confounding an attempt to analyze mother-initiated therapy.

\section{Outcome measures}

The outcome measures are the mother's possession and use of medications and medical appliances for the index child. Our interest was in different categories of medications rather than in actual numbers of medications; the latter would have required eliciting information concerning possession of multiple products in the same category (e.g. Robitussin and Triaminicol in addition to asking the mother about cough medicines in general).

'Medications possessed' was defined as the sum of different categories named in reply to four questions: medications used last lime the mother gave child NPM; medications kept in the house for use in case child becomes ill; a checklist of 19 categories of medications (to stimulate recollection of categories not volunteered in the prior open-ended questions); and any other medicines kept in house for child. The mother was also asked 'how often in an average year' she used each previously-named medication for the child. 'Medications used' was defined as the sum of different categories identified as administered at least once in an average year. The scores for number of different categorics of medications possessed ranged from 1 to 16 ; for number of categories used, the range was $1-13$.

The same approach was employed in quantifying possession and use of different types of medical appliances. 'Appliances possessed' was defined by the mother's selection, from a list of 7 medical appliances, of those kept in the house for use for her children. 'Appliances used' was based on the mother's report of whether or not she had used the appliance for the index child. The number of types of appliances mentioned by each mother was summed to create appliance possession and use score; the results ranged from 0 to 7 for types of appliances possessed, and from 0 to 6 for types of appliances used.

The various category lists were developed in consultation with experts in pediatrics to ensure reasonably comprehensive inclusion of the types of medications and medical appliances likely to be used in mother-initiated treatment. The definitions of each of the dependent variables, including the category lists, and their coding are provided in Appendix A. 


\section{Attitudinal measures and index construction}

Two indices based on variables found in models of health-related decision making [14] were constructed: perceptions of 'vulnerability to illness' and of 'benefits of treatment". From a list of 13 acute pediatric health problems*, mothers were asked to estimate, on 7-point scales, both the chance that their child might get each condition (from $1=$ no chance to $7=$ almost certain) and how well an OTC medication would work for that condition (from $1=$ not work well to $7=$ work very well). The health problems werc chosen from lists of conditions commonly employed in research [15-17] and from consultation with pediatric experts. Each index score averaged the mother's responses on the 7-point scale; the mean scores and the coefficients of reliability $(\alpha)$ for the 'perceived vulnerability' and 'perceived efficacy of OTCs' indices were 2.79 and 4.37 and 0.73 and 0.81 , respectively.

Three scales were derived by principal-component factor analysis from a set of 12 health and medication opinion statements, using orthogonal rotation and applying the varimax criterion (these three of the five resulting attitude clusters accounted for $85 \%$ of the variance in the set of items) (factor loadings for each item and reliability coefficients for factor scales are presented in Appendix B). Factor 1, 'propensity to initiate medication', consists of three items concerned with the mother's keeping medications in the home for both the child and herself $(\alpha=0.62)$. Factor 2, 'benefit of OTCS', contains items regarding perceived therapeutic effectiveness of OTCs for both the child's and mother's illnesses $(\alpha=0.60)$. Factor 3, 'frequency of health problems', has items that indicate salience of sickness $(\alpha=0.53)$. For each factor, an index was computed as the summated score of the mother's agreement with items having substantial loadings $(0.45$ or higher $)[18,19]$.

In addition, two items neither loading substantially nor fitting the factors on a face validity basis were employed as single variables because findings from previous research suggest their influence on the likelihood of mothers" undertaking medically-advocated behaviors on behalf of their children [20, 21]. These items were : 'Events usually take their own course no matter what you do' (a locus-of-control measure); and 'In general, when I get sick, I try things at home for a few days to see if I can take care of the problem myself"

\section{Index of $S E S$}

An index of socioeconomic status (SES) was constructed based on mother's education and total annual family income. First, education was coded as a continuous variable (years of school completed) and income was categorized into eight levels (< $\$ 5000 ; \quad \$ 5000-\$ 7999 ; \quad \$ 8000-\$ 11,999$ $\$ 12.000-\$ 14.999 ; \$ 15,000-\$ 17,999 ; \$ 18,000-\$ 19,999$;

* The health problems included in this list were: earache (pain not infection); sore throat (viral); throwing up a few times during the day; diarrhea for several days; scratch on arm or leg; sneezing a lot because of allergy; constipation: mild skin rash; cough for two days; a fever of $101^{\prime}:$ trouble getting to sleep; toothache; and belly pain.
$\$ 20,000-\$ 29,999 ; \$ 30,000$ or more). Second, codes for education (weighted 1.5) and income were summed, and resultant scores, ranging from 6.0 to 33.5 , were assigned to four SES groups: Low $(N=119)$; Lower Middle $(N=112)$; Upper Middle $(N=138)$; and High $(N=131)$. The weighting was based on Green"s [22] technique for scoring research on mothers' preventive health actions for children.

\section{Judges' ratings: judges and evaluation information}

A panel of six pediatricians evaluated mothers independent use of medications for their children. The judges were selected to represent three areas of relevant expert opinion: two pediatricians delivering ambulatory care in private practices (located in Rochester, N.Y.); two pediatricians delivering ambulatory care in university teaching hospital clinics (at other institutions); and two pediatricians with specialty training in pediatric pharmacology (at other institutions). The judges reviewed each mother's reports of different categories of medications used, as well as the original data on the perceived problem for which the medication was used, dose administered, how often administered per day, and duration of administration. While the judges were blinded with regard to other study data (e.g. mother's sociodemographic characteristics and attitudes), the index child's age, sex and weight were provided to assist in their evaluations.

\section{Judges' ratings: scales and procedures}

Three separate 11-point rating scales were employed for every medication mentioned. Judges rated the "usefulness' of the drug for the problem the mother perceived her child to have, from $0=$ not useful to $10=$ useful (mean $=6.88$ ). The scale for 'correctness' of the manner of administration (i.e. dose administered, how often administered and duration of administration) in relation to the perceived problem ranged from $0=$ not correct to $10=$ correct (mean $=7.02$ ). Finally, in assessing the probable 'harmfulness or helpfulness' of the mother's medication use, judges rated the clinical value of the drug for the problem and the way the drug was being used on a scale from $0=$ probably harmful, to $5=$ neither harmful nor helpful, to $10=$ probably helpful (mean $=6.86)$. Each judge independently rated all reported instances of medication use (total $N=3908$ ). Since there were six judges, each mother received 6 ratings for each of the 3 evaluated dimensions of MIMB (i.e. usefulness, correctness and harmfulness/helpfulness).

In addition, each evaluation instrument contained a summary 'overall appropriateness' scale wherein the judges were to take into consideration the com. plete documentation of the mother's use of OTCs and leftover prescription medications for the child. This scale ranged from $0=$ generally inappropriate medication user to $10=$ generally appropriate medication user (mean $=6.88$ ). Each mother received six "overall appropriateness' ratings. The final scale scores were an average of the ratings of the six judges for each mother. Scale scores were calculated for each evaluative dimension by all medication use, and for 'overall appropriateness' ratings. 
Table 1. Mothers possessing and using different numbers of categories of medications and types of medical appliances for their children

\begin{tabular}{|c|c|c|c|c|c|c|c|c|c|}
\hline \multirow{3}{*}{$\begin{array}{l}\text { Number of } \\
\text { categories }\end{array}$} & \multicolumn{4}{|c|}{ Medication categories } & \multirow{3}{*}{$\begin{array}{c}\text { Number of } \\
\text { types }\end{array}$} & \multicolumn{4}{|c|}{ Appliances } \\
\hline & \multicolumn{2}{|c|}{ Possessed } & \multicolumn{2}{|c|}{ Used } & & \multicolumn{2}{|c|}{ Possessed } & \multicolumn{2}{|c|}{ Used } \\
\hline & $N$ & $\%$ & $N$ & $\%$ & & $N$ & $\%$ & Y & $\%$ \\
\hline $1-3$ & 82 & 16.4 & 107 & 21.4 & 0 & 10 & 2.0 & 29 & 5.8 \\
\hline $4-6$ & 184 & 36.8 & 234 & 46.8 & $1-2$ & 95 & 19.0 & 186 & 37.2 \\
\hline $7-9$ & 160 & 32.0 & 134 & 26.8 & 3 & 76 & 15.2 & 161 & 32.2 \\
\hline $10-13$ & 66 & 13.2 & 25 & 5.0 & $4-6$ & 291 & 58.2 & 124 & 24.8 \\
\hline $14-16$ & 8 & 1.6 & - & - & 7 & 28 & 5.6 & - & - \\
\hline Total & 500 & 100.0 & 500 & 100.0 & Total & 500 & 100.0 & 500 & 100.0 \\
\hline
\end{tabular}

\section{Sociodemographic characteristics}

The median age of the 500 mothers was 31 years, and $345(69 \%)$ were white and $155(31 \%)$ were nonwhite, of which $135(27 \%)$ were black. Median educational level (highest grade completed) achieved was high school graduation, and median category of total annual family income was $\$ 15,000-\$ 17,999$ a year. The study population closely resembled the adult population of Rochester, N.Y. and the surrounding suburban area on all above characteristics as reported in the 1980 census [23]. The majority of mothers $(58 \%)$ had one to 2 children. In terms of presence of older siblings, which was posited to be an indicator of previous experience in caring for children's symptoms and illnesses and predicted to be associated with higher levels of MIMB, $40 \%$ of mothers had children older than the index child. Fifty-three percent of the index children were male.

\section{RESULTS}

Extent of possession and use of medications and medical appliances

Findings shown in Table 1 reveal that almost half $(48 \%)$ of the sample of mothers kept 7 or more different categories of medications on hand for their children (15\% kept 10 or more), and approximately one-third $(32 \%)$ reported using 7 or more different categories of medications for their children during an average year. In addition, more than one-third $(37 \%)$ to slightly less than one-half $(47 \%)$ of the subjects possessed or used at least 4-6 different categories of medications for their children. Indeed, it is noteworthy that none of the mothers said thay did not keep such medications around the house (only 16\% kept 3 or fewer categories), and that no mother reported not using any medications for her child.

A similar pattern is evidenced by the wide variety of medical appliances that mothers possess and use for their children. Almost two-thirds $(64 \%)$ of mothers kept 4 or more different medical appliances on hand, and a quarter of the sample used at least 4 of these appliances for the index child. Only $2 \%$ reported not owning any of these appliances, and only $6 \%$ had not used any appliances for the index child.

Socioeconomic status variations in possession and use of medications and medical appliances

Table 2 depicts the relationship between SES and possession and use for different numbers of categories of medications and for numbers of medical appliances. The overall mean scores show that mothers possess an average of 6 different categories of medications and use an average of 5 for their children. In addition, they keep an average of 4 appliances in the home and use about 3 for their children.

Data from the one-way analyses of variance for mean scores on the dependent variables reveal a consistent, linear and statistically significant trend: the higher the SES of the mother, the greater the degree of possession and use of NPMs and medical appliances $(P<0.001)$. This increase reflects considerable differences between the two 'highest' and the two 'lowest' SES groups. High SES mothers keep

Table 2. Mean scores for numbers of categories of medications and appliances possessed and used by mothers for their children, by sociocconomic status

\begin{tabular}{|c|c|c|c|c|c|c|}
\hline \multirow[b]{2}{*}{$\begin{array}{l}\text { Medications or } \\
\text { appliances for child }\end{array}$} & \multicolumn{6}{|c|}{ Socioeconomic status } \\
\hline & $\begin{array}{c}\text { Sample } \\
\text { mean } \\
(N=500)\end{array}$ & $\begin{array}{c}\text { Low } \\
(N=119)\end{array}$ & $\begin{array}{c}\text { Lower } \\
\text { Middle } \\
(N=112)\end{array}$ & $\begin{array}{c}\text { Upper } \\
\text { Middle } \\
(N=138)\end{array}$ & $\begin{array}{c}\text { High } \\
(N=131)\end{array}$ & $\begin{array}{l}\text { ANOVA } \\
(P \text {-value })\end{array}$ \\
\hline $\begin{array}{l}\text { Number of different } \\
\text { categories of } \\
\text { medications possessed }\end{array}$ & $\begin{array}{c}6.45 \\
(2.96)\end{array}$ & $\begin{array}{c}4.37 \\
(2.23)\end{array}$ & $\begin{array}{c}5.46 \\
(2.46)\end{array}$ & $\begin{array}{c}7.27 \\
(2.76)\end{array}$ & $\begin{array}{c}8.33 \\
(2.60)\end{array}$ & 0.001 \\
\hline $\begin{array}{l}\text { Number of different } \\
\text { categories of } \\
\text { medications used }\end{array}$ & $\begin{array}{c}5.49 \\
(2.37)\end{array}$ & $\begin{array}{c}4.05 \\
(2.02)\end{array}$ & $\begin{array}{c}4.85 \\
(1.99)\end{array}$ & $\begin{array}{c}6.12 \\
(2.18)\end{array}$ & $\begin{array}{c}6.68 \\
(2.31)\end{array}$ & 0.001 \\
\hline $\begin{array}{l}\text { Number of types of } \\
\text { appliances possessed }\end{array}$ & $\begin{array}{c}4.04 \\
(1.73)\end{array}$ & $\begin{array}{c}2.66 \\
(1.60)\end{array}$ & $\begin{array}{c}3.60 \\
(1.70)\end{array}$ & $\begin{array}{c}4.59 \\
(1.36)\end{array}$ & $\begin{array}{c}5.11 \\
(1.19)\end{array}$ & 0.001 \\
\hline $\begin{array}{l}\text { Number of types of } \\
\text { appliances used }\end{array}$ & $\begin{array}{c}2.68 \\
(1.39) \\
\end{array}$ & $\begin{array}{l}1.58 \\
(1.13)\end{array}$ & $\begin{array}{c}2.37 \\
(1.26) \\
\end{array}$ & $\begin{array}{c}3.16 \\
(1.23) \\
\end{array}$ & $\begin{array}{c}3.43 \\
(1.16) \\
\end{array}$ & 0.001 \\
\hline
\end{tabular}

Note: standard deviation is indicated in parentheses. 
Table 3. Correlation ( $\gamma$ ) between number of categories of medication and types of medical appliances possessed and used. and health related attitudes of mothers

\begin{tabular}{|c|c|c|c|c|c|}
\hline \multirow[b]{2}{*}{ Attitude variable } & \multirow[b]{2}{*}{$N$} & \multicolumn{2}{|c|}{$\begin{array}{c}\text { Number of } \\
\text { medication categories }\end{array}$} & \multicolumn{2}{|c|}{ Number of appliances } \\
\hline & & Possessed & Used & Possessed & Used \\
\hline Perceived vulnerability (index) & 500 & $0.191+$ & $0.146^{*}$ & $0.120^{*}$ & $0.178+$ \\
\hline Perceived efficacy of OTCs (index) & 500 & $0.331+$ & $0.341+$ & $0.210+$ & $0.255+$ \\
\hline $\begin{array}{l}\text { Benefits of OTCs for (child's) illnesses } \\
\text { Benefits of OTCs for (mother's) illncsses } \\
\text { Benefits of OTCs (index) }\end{array}$ & $\begin{array}{l}499 \\
500 \\
499\end{array}$ & $\begin{array}{l}0.148+ \\
0.141+ \\
0.230+\end{array}$ & $\begin{array}{l}0.101^{*} \\
0.121^{*} \\
0.183^{\dagger}\end{array}$ & $\begin{array}{l}0.053 \\
0.046 \\
0.083\end{array}$ & $\begin{array}{l}0.084 \\
0.029 \\
0.107\end{array}$ \\
\hline $\begin{array}{l}\text { Saves Rx meds. for (child) } \\
\text { Keeps meds. in home for (child) } \\
\text { Keeps meds. in home for self } \\
\text { Propensity to initiate medication (index) }\end{array}$ & $\begin{array}{l}499 \\
499 \\
500 \\
498\end{array}$ & $\begin{array}{l}0.233 \dagger \\
0.383 \dagger \\
0.225 \dagger \\
0.314 \dagger\end{array}$ & $\begin{array}{l}0.255 \dagger \\
0.404 \dagger \\
0.234 \dagger \\
0.334 \dagger\end{array}$ & $\begin{array}{l}0.083 \\
0.247+ \\
0.064 \\
0.140^{+}\end{array}$ & $\begin{array}{r}0.145^{*} \\
0.282 \dagger \\
-0.036 \\
0.157 \dagger\end{array}$ \\
\hline $\begin{array}{l}\text { Family troubled by sickness } \\
\text { Mother troubled by sickness } \\
\text { Frequency of health problems (index) }\end{array}$ & $\begin{array}{l}500 \\
500 \\
500\end{array}$ & $\begin{array}{l}0.200+ \\
0.084 \\
0.134+\end{array}$ & $\begin{array}{l}0.243+ \\
0.094 \\
0.156 \dagger\end{array}$ & $\begin{array}{l}0.171+ \\
0.057 \\
0.094\end{array}$ & $\begin{array}{l}0.162+ \\
0.023 \\
0.083\end{array}$ \\
\hline Self-carc for own ilinesses & 500 & $0.214^{+}$ & $0.235 t$ & 0.052 & $0.164 t$ \\
\hline Events take own course & 496 & $-0.165 t$ & $-0.147 \dagger$ & $-0.204+$ & $-0.258+$ \\
\hline
\end{tabular}

Note: totals vary because of missing values.

$* P<0.05:+P<0.01$

available for their children almost twice as many NPM categories as do Low SES mothers; the comparable SES difference for use is one and a half times. Similarly, for medical appliances, High SES mothers possess and use twice as many different types as do Low SES mothers.

\section{Effects of attitudinal factors on possession and use of} medications and medical appliances

Results presented in Table 3 permit examination of the relationships between mothers' medicationrelated attitudes and health concerns and the four dependent measures of mother-initiated treatment behaviors, possession and use of different numbers of categories of medications and medical appliances. Mothers' responses to the two indices based on the list of children's potential health problems ('perceived vulnerability' and 'perceived efficacy of OTCs') were significantly correlated with all four dependent variables. The strongest associations were obtained for mothers' beliefs in how well OTCs work for children's health problems. Since only 1 of the 7 medical appliances listed (fever thermometer) is directly relevant to a condition on the list of potential health problems (i.e. fever), the significant correlations obtained between the attitude indices and the appliance dependent variables may be due in part to the high intercorrelations obtained between the numbers of different categories of medications and appliances possessed $(r=0.509)$ and used $(r=0.536)$.

By contrast, the associations of medication-specific attitudes with appliances possessed and used are not usually significant-and, in those instances where they are, the strength of the associations is lower than for the corresponding medication dependent variables (the single exception is the gamma between the 'perceived vulnerability' index and number of types of appliances used). However, the two items measuring non-medication-directed perceptions ("extent to which family is troubled by sickness' and 'locus-ofcontrol") are significantly associated with appliances possessed and used.

The associations of the 'benefits of OTCs' and 'propensity to initiate medication' indices with each of the four measures of MIMB are in the predicted direction, but the correlations with appliance possession and use are not uniformly significant. For the former index (and its separate items), mothers who keep and use more medications are significantly more likely to feel that OTCs are beneficial in the treatment of their children's and their own illnesses. Of the three items in the 'propensity to initiate medication' index, the most powerful was 'I try to keep a variety of medicines at home in case (child) gets sick and needs them'; however the index (which summarizes a wider attitudinal range) also produced strong correlations $(P<0.01)$ with the outcome measures.

It is evident that, although the 'frequency of health problem' index is significantly related to medication possession and use, this relationship stems from the mother's perception that her family is often troubled by sickness rather than from her own illness experience. Finally, mothers who attempt self-treatment at the onset of their own illnesses and who disagreed with the statement 'events usually take their own course no matter what you do' (i.e. exhibit an internal locus of control) are significantly more likely to possess and to use medications and medical appliances for their children.

\section{Effects of sociodemographic and attitudinal factors multiple regressions}

To examine the relative importance of mothers' personal characteristics and opinions in predicting MIMB, multiple regression analyses were employed. Prior to these analyses, intercorrelations (Pearson $r$ 's) among the 10 predictor variables were calculated. Since nonparametric correlations (GoodmanKruskal's Gammas) yielded virtually the same results in terms of statistical significance as those obtained from the Pearson $r$ 's, it was decided to use parametric statistics for the ordinally-scaled measures based on the rationale provided by Labovitz [24]. The relatively-low magnitude of these correlations (with the exception of that between education of mother and family income) suggests the indicators are 
Table 4. Regression of medication possession and use on sociodemographic and attitudinal variables $(N=493)$

\begin{tabular}{lcccc}
\hline & \multicolumn{2}{c}{$\begin{array}{c}\text { Number of medication } \\
\text { categories possessed }\end{array}$} & \multicolumn{2}{c}{$\begin{array}{c}\text { Number of medication } \\
\text { categories used }\end{array}$} \\
Variables & $\beta$ & $t$ & $\beta$ & $t$ \\
\hline Education of mother & 0.222 & $4.69^{+}$ & 0.169 & $3.38^{+}$ \\
Family income & 0.345 & $7.27^{+}$ & 0.309 & $6.12^{+}$ \\
Number of children & 0.065 & 1.64 & 0.048 & 1.14 \\
Child(ren) older than index child & 0.078 & $1.98^{*}$ & 0.066 & 1.58 \\
Perceived vulnerability (index) & 0.079 & $2.17^{*}$ & 0.084 & $2.16^{+}$ \\
Perceived efficacy of OTCs (index) & 0.132 & $3.64^{\dagger}$ & 0.152 & $3.96^{+}$ \\
Propensity to initiate medication (index) & 0.196 & $5.43^{+}$ & 0.203 & $5.30^{+}$ \\
Frequency of health problems (index) & 0.099 & $2.66^{\dagger}$ & 0.110 & $2.81+$ \\
Self-care for own illnesses & 0.094 & $2.63+$ & 0.080 & $2.13^{*}$ \\
Events take own course & 0.022 & 0.62 & 0.018 & 0.47 \\
Multiple $R$ & 0.660 & $F=37.133$ & 0.603 & $F=27.593$ \\
$R^{2}$ & 0.435 & & 0.364 & \\
\hline$* P<0.05 ;+P<0.01$ & & & &
\end{tabular}

sufficiently independent to preclude concern that multicolinearity would materially influence the results of regression analyses. The associations between the attitudinal variables and sociodemographic variables were not consistently significant and the relationships among the 6 attitudinal variables were either not significant or of a low magnitude of significance.

When medication possession and use are regressed on sociodemographic and attitudinal variables (Table 4 ), 44 and $36 \%$ of the variance (respectively) in mothers' medication behaviors is accounted for. A more detailed inspection of these regression results reveals meaningful differences in the relative size and level of significance of the betas for the two medication behavior variables. Mothers who report possession of a greater number of different categories of medications are significantly more likely $(P<0.01)$ to have completed a higher level of education $(\beta=0.222)$ and to have a higher family income $(\beta=0.345)$. Perhaps surprisingly, the number of children in the family does not significantly influence MIMB, and the presence of children older than the index child is related only to medications kept available (and then, only at the $P<0.05$ level). For mothers reporting use of a greater number of different categories of medications, the betas for education and income are somewhat lower (0.169 and 0.309) than those obtained for possession, but they continue to reach significance beyond the 0.01 level. However, the remaining sociodemographic variables are not related to medication use.
Table 4 also provides evidence of the contribution of attitudes to the explanation of medication possession; 5 of the 6 attitudinal variables are significantly related to medication possession, with the 'propensity to initiate medication' index yielding the largest beta. Mothers who keep more different categories of medications available for their children are more likely to indicate that they consider OTCs to be effective in treating their children's health problems $(\beta=0.132)$, and they are more predisposed to initiate use of medications for their children and themselves $(\beta=0.196)$. These mothers also tend to perceive the child as vulnerable to illness and their families as more often troubled by sickness, and are more likely to attempt self-care at the onset of their own illnesses. These attitudinal variables are similarly related to medication use, with 'perceived efficacy of OTCs' ( $\beta=0.152)$ and 'propensity to initiate medication' $(\beta=0.203)$ indices assuming the greatest importance (the locus-of-control item did not produce any significant betas in these regressions). In summary, both sociodemographic and attitudinal variables make significant contributions to explanation of variance in medication possession and use.

For appliance possession and use, corresponding regressions explain 38 and $34 \%$ of the variance, respectively (see Table 5 ). The pattern for sociodemographic variables is similar to that obtained from the regressions for MIMB. Mothers who report possession and use of a greater number of medical appliances are significantly more likely $(P<0.01)$ to have higher family incomes $(\beta=0.399$ and 0.354$)$

Table 5. Regression of appliance possession and use on sociodemographic and attitudinal variables $(N=493)$

Number of appliances Number of appliances

possessed

used

\begin{tabular}{lllll} 
Variables & $\beta$ & $t$ & $\beta$ & $t$ \\
\hline Education of mother & 0.194 & $3.91 \dagger$ & 0.167 & $3.26^{+}$ \\
Family income & 0.399 & $8.04 \dagger$ & 0.354 & $6.89 \dagger^{\dagger}$ \\
Number of children & 0.069 & 1.65 & 0.011 & 0.26 \\
Child(ren) older than index child & 0.106 & $2.58 \dagger$ & 0.089 & $2.08^{*}$ \\
Perccived vulncrability (index) & 0.038 & 0.99 & 0.087 & $2.21^{*}$ \\
Perceived efficacy of OTCs (index) & 0.061 & 1.60 & 0.067 & 1.72 \\
Propensity to initiate medication (index) & 0.073 & 1.93 & 0.097 & $2.49^{*}$ \\
Frequency of health problems (index) & 0.117 & $2.99+$ & 0.057 & 1.43 \\
Seif-care for own illnesses & 0.035 & 0.93 & 0.035 & 0.90 \\
Events take own course & 0.050 & 1.34 & 0.109 & $2.81 \dagger$ \\
Multiple $R$ & 0.615 & $F=29.278$ & 0.581 & $F=24.590$ \\
$\mathrm{R}^{2}$ & 0.378 & & 0.339 & \\
\hline$* P<0.05+P<0.01$ & & & &
\end{tabular}


and to have completed higher levels of education $(\beta=0.194$ and 0.167$)$. Number of children is not significant, while the presence of older children is predictive of appliances kept $(\beta=0.106)$ and used $(\beta=0.089)$.

However, none of the attitudinal variables is a consistent predictor of appliance possession and use. The 'propensity to initiate medication' index is significant $(P<0.05)$ but the beta is lower than in the regression for medications used. As was found for medication possession, mothers who possess more different types of appliances for their children are more likely to view their families as troubled by sickness $(\beta=0.117)$. However, perceptions of the child's vulnerability to illness $(\beta=0.038)$, opinions about the effectiveness of OTCs in treating their child's health problem $(\beta=0.061)$ and resorting to self-care for own illnesses $(\beta=0.035)$ were not significant contributors to keeping medical appliances in the home.

Attitudes fare better in their relationship to appliance use. The 'perceived vulnerability' and 'propensity to initiate medication' indices both make significant contributions to explained variance $(\beta=0.089$ and 0.097$)$; and, similarly to the regression results obtained for MIMB, the highest attitude-item beta is produced by the mother's proclivity to view life events in a less fatalistic manner $(\beta=0.109)$.

\section{Expert judges' ratings of mothers' use of medications}

The next step in the analyses was to explore the results of the judges' ratings of all instances of medication use $(N=3908)$ reported by the study mothers. Interjudge agreement (reliability) was assessed by employing an intraclass correlation coefficient of internal consistency, Cohen's kappa $(\kappa)$ statistic [25], which can range from -1 (perfect disagreement) to +1 (perfect agreement). Since the rating scale contained 11 points, we interpreted two adjacent responses as qualitatively similar; thus, ratings within 1 point, were counted as 'agreement' and ratings differing by 2 points were weighed as 'half agreement'.

For each evaluative dimension, the coefficient is positive, resulting in the following values of interjudge median $\kappa$ : usefulness $=0.47$; correctness $=0.25 ; \quad$ harmfulness $/$ helpfulness $=0.52 ; \quad$ and overall appropriateness $=0.33$. Although resultant kappas were moderate to fair, they are significantly greater than expected from chance alone $(P<0.05)$, with the exception of the 'correctness' of manner of administration.

The mean scores and standard deviations (overall and by SES of mother) for each evaluative dimension are presented in Table 6 . In general, the mean ratings on each dimension for the total sample indicate only a moderate level of satisfaction by the judges with the ways in which mothers used medications. In each instance the rating is moderately higher than the median or neutral scale point (5.0).

Data from one-way analyses of variance on the judges' mean score ratings of MIMB show a significant $(P<0.001)$ linear association with mothers' SES. With regard to every dimension along which the judges assessed MIMB (i.e. 'usefulness' of the drug for the problem, 'correctness' of the manner of administration, and 'harmfulness or helpfulness' of the mother's medication use), the judges' scores increased concomitantly with mothers' SES. It should be noted that the clinical value of medications for problems mothers perceive their children to have (the 'harmfulness or helpfulness' dimension) consistently received the lowest relative ratings, whether compared with the total study sample or by SES category. All the mean scores for each dimension by SES display ratings indicating only a moderate level of satisfaction.

The 'overall appropriateness' scores also reflect reserved endorsement of mothers' medication behaviors; these ratings are also related to SES in the predicted direction, and are significant beyond the 0.01 level.

A series of additional correlational and regression analyses were conducted to specify the relationship of mothers' attitudes and sociodemographic characteristics to the judges' ratings. Results from these analyses indicated that, although mothers' attitudes were found to be related to the possession and use of different numbers of categories of medications and appliances, these attitudes were only weakly associated with the evaluative dimensions considered in the expert judges' ratings and contributed little to explained variance in those ratings. As would be anticipated from the analysis of variance results, sociodemographic variables (particularly mothers' education levels) were more predictive of the judges' ratings.

Table 6. Mean scores for judges' ratings of medications used by mothers for their children, by socioeconomic status

\begin{tabular}{|c|c|c|c|c|c|c|}
\hline \multirow[b]{2}{*}{$\begin{array}{l}\text { Judges ratings } \\
\text { dimension }\end{array}$} & \multicolumn{6}{|c|}{ Socioeconomic status } \\
\hline & $\begin{array}{c}\text { Sample } \\
\text { mean } \\
(N=500)\end{array}$ & $\begin{array}{c}\text { Low } \\
(N=119)\end{array}$ & $\begin{array}{c}\text { Lower } \\
\text { Middle } \\
(N=112)\end{array}$ & $\begin{array}{c}\text { Upper } \\
\text { Middle } \\
(N=138)\end{array}$ & $\begin{array}{c}\text { High } \\
(N=131)\end{array}$ & $\begin{array}{l}\text { ANOVA } \\
(P \text {-value })\end{array}$ \\
\hline Usefulness & $\begin{array}{c}6.88 \\
(0.76)\end{array}$ & $\begin{array}{c}6.53 \\
(1.01)\end{array}$ & $\begin{array}{c}6.80 \\
(0.74)\end{array}$ & $\begin{array}{c}7.03 \\
(0.60)\end{array}$ & $\begin{array}{c}7.11 \\
(0.50)\end{array}$ & 0.001 \\
\hline Correctness & $\begin{array}{c}7.02 \\
(0.69)\end{array}$ & $\begin{array}{c}6.61 \\
(0.95)\end{array}$ & $\begin{array}{c}7.04 \\
(0.49)\end{array}$ & $\begin{array}{c}7.12 \\
(0.57)\end{array}$ & $\begin{array}{c}7.27 \\
(0.47)\end{array}$ & 0.001 \\
\hline Harmful helpfulness & $\begin{array}{c}6.68 \\
(0.50)\end{array}$ & $\begin{array}{c}6.41 \\
(0.64)\end{array}$ & $\begin{array}{c}6.62 \\
(0.44)\end{array}$ & $\begin{array}{c}6.76 \\
(0.41)\end{array}$ & $\begin{array}{c}6.88 \\
(0.34)\end{array}$ & 0.001 \\
\hline Overall appropriateness & $\begin{array}{c}6.88 \\
(0.64)\end{array}$ & $\begin{array}{c}6.50 \\
(0.81)\end{array}$ & $\begin{array}{l}6.81 \\
(0.63)\end{array}$ & $\begin{array}{c}7.00 \\
(0.48)\end{array}$ & $\begin{array}{c}7.17 \\
(0.42)\end{array}$ & 0.001 \\
\hline
\end{tabular}

Note: standard deviation is indicated in parentheses. 


\section{DISCUSSION}

Our results indicate that most mothers keep available and use a considerable number of different categories of medications and appliances, and corroborate previous findings $[6,8]$ that children of better-educated and higher-income mothers receive more NPMs. In addition to demonstrating a direct relationship between mothers' SES and degree of MIMB, further analyses (multiple regression) of the separate influences of income and education revealed that, while both play important roles, level of income was somewhat more productive in accounting for numbers of medication categories possessed and used, and was substantially more important in explaining numbers of medical appliances possessed and used.

Of potential concern, when looking at the linear relationship between mothers' SES and the degree of MIMB, is the possible contribution of race and/or of the different study sites to variation in MIMB. However, hierarchical regression analyses demonstrate that, after mother's SES and race are entered into the equation, study site accounts for only an additional $4 \%$ of the variance in number of medications possessed; $2 \%$ for medications used; $1 \%$ for appliances possessed; and $2 \%$ for appliances used. Moreover, when each of the four measures of MIMB are regressed on SES and study site, the amount of variance explained was only $2 \%$ less for each dependent variable than was obtained by the corresponding three-variable hierarchical regression equation. Thus, by far, the major contributing factor in the explanation of the variance in MIMB is mother's SES.

When zero-order correlations were calculated between mothers' sociodemographic characteristics and MIMB, the magnitude of the correlations for education and income confirm the results obtained from the explanatory multiple regressions, with income producing the higher coefficients. Other associations depict the mother who engages in higher levels of MIMB as older and (with the exception of medical appliances) as having children older than the index child. The nonsignificant correlations between child's age or sex and mother's medication possession and use parallel those of previous investigations from Britain and the United States of parent-initiated use of NPMs [6, 10]; and, for possession and use of medical appliances, the weak associations obtained suggest that behavior is mildly influenced by the index child being older, perhaps because several of the appliances included in the list (e.g. ace bandage, heating pad) may be more appropriate for older children.

Our results did not substantiate prior findings from Britain [6] that children from smaller families are more likely to receive NPMs. However, the significant correlations obtained between presence of children older than the index child and each of the four dependent measures support our hypothesis that mothers with prior experience in treating children's symptoms and illnesses would be more likely to keep medications and appliances in the home and to initiate therapies.

The study indicates that attitudes are important in understanding MIMB. Mothers ${ }^{\circ}$ perceptions of their children's susceptibility to potential health problems. and of the effectiveness of OTC medications for treating potential health problems. were significantly associated with possessing and using a greater number of categories of medications and medical appliances. Medication-specific attitudes also contributed to explaining MIMB; the mother who keeps available and uses for her child a greater number of categories of medications is more likely to regard OTCs as beneficial in the treatment of illnesses (both her child's and her own), to display an attitudinal predisposition to keep medications in the home in the event she or the child should get sick, and to rely on self-care to manage her own illnesses. In addition, she perceives her family as being more frequently troubled by sickness and feels more able to control events by personal intervention.

A major conclusion to be drawn from these data is that both sociodemographic and attitudinal factors contribute to understanding MIMB. Regression analyses revealed that a combination of sociodemographic and attitudinal variables could account for substantial portions of the variance in MIMB: 44 and $36 \%$ of variance in possession and use of different categories of medications, and 39 and $34 \%$ of variance in possession and use of medical appliances. These figures compare favorably with other studies attempting to explain a variety of illness behaviors $[20,26-28]$.

The limitations of the present study should be noted. On a conceptual level, we did not attempt to examine all of the factors which the medical sociology literature might proffer as possibly related to MIMB (e.g. social network influences, ethnicity, access to medical care, situational stress) [29-31]. Similarly, this is not a study of lay health beliefs of mothers, i.e. the meaning of symptoms, meaning of illness, etc. (and, therefore, that literature has not been reviewed). Rather the focus of the investigation is more narrowly defined: exploring the determinants of the use of available medicines to treat perceived physical symptoms in the absence of medical advice within the context of our interest in the influence of psychosocial and demographic factors. Finally, from the explanatory perspective there still remains much to be learned. Although the relative magnitude of the contribution of education and income is documented, the study cannot explain precisely what it is about social class that drives different medication behaviors (i.e. why should more educated mothers be more concerned about symptoms, such as cough or sore throat, in their children).

From the perspective of generalizability, it is relevant that although our population was from two study sites it was found to be representative when compared to 1980 census information for Rochester, N.Y. Since the sample was from a single city, the findings may not apply to other United States cities. On the other hand, the city is not atypical in terms of education, income and racial mix. Furthermore, generalizations from this study are appropriate only to the United States (although components of the findings corroborate those of previous investigations in Britain).

The present study also extends existing research on 
parent-initiated therapies for children to the domain of MIMB quality assessment. The evaluations by expert judges indicate minimal support for mothers' choice and manner of administration of medications for perceived health problems in their children. Further, although the quality of MIMB improves as mothers' SES increases, the modest level of satisfaction of the judges extended to mothers in all SES groups.

These evaluative results need to be tempered by the limitations imposed by the variation found in appropriateness of prescribing practices of clinicians. We are not concluding that mothers' use of medications was either 'good' or 'bad'-only that experts in pediatrics advocated only minimal approval.

A limitation in the present analyses of these evaluations is that data aggregation does not permit determination of whether there are specific perceived health problems in children or use of specific categories of medications where the mothers' therapeutic attempts may be of greater (or lesser) clinical concern with regard to the study evaluation dimensions. Future analyses should also address the issue of whether SES variations occur in problem-specific or category-specific evaluations.

Our investigation found MIMB to be an extensive and widespread phenomenon involving therapies that are frequently used in a clinically-questionable manner. Health care providers should be encouraged to routinely counsel mothers regarding the appropriate use of self-initiated medication, become familiar with the SES-medication use patterns of mothers of their patients, and should also question the mother concerning actions she may have undertaken prior to bringing the child for treatment. This educational role of health care providers is responsive to the suggestions of the international working group (from 16 countries) on minimum information needed by the general public for sensible self-initiated medication use [32]. The relationships observed between MIMB and various sociodemographic and attitudinal variables suggest foci and dimensions for future health education intervention strategies aimed at increasing mothers' abilities to intervene effectively in the management of different symptoms and illnesses in their children.

\section{REFERENCES}

I. Drug Topics. 20 August, 1981

2. Dunnell K. and Cartwright A. Medicine Takers, Prescribers and Hoarders. Routledge \& Kegan Paul, New York, 1972.

3. Knapp D. A. and Knapp D. E. Decision-making and self-medication. Am. J. Hosp. Pharm. 29, 1004-1012, 1972.

4. Bush P. J. and Osterweis M. Pathways to medicine use. J. Hlth soc. Behat, 19, 179-189, 1978.

5. Johnson R. E. and Pope C. R. Health status and social factors in nonprescribed drug use. Med. Care 21, 225-233. 1983.

6. Jefferys M., Brotherston J. H. F. and Cartwright A Consumption of medicines on a working-class housing estate. Br. J. Pret. soc. Med. 14, 64-76, 1960.

7. Haggerty R. J. and Roghmann K. J. Noncompliance and self-medication. Pediatr. clin. N. Am. 19, 101-115. 1972 .
8. Maiman L. A., Becker M. H., Cummings K. M. Drachman R. H. and O'Connor P. A. Effects of sociodemographic and attitudinal factors on mother-initiated medication behavior for children. Publ. Hlth Rep. 97, 140-149, 1982.

9. Ames J. T., Hayden G. F., Campbell R. E. and Lohr J. A. Parents' conception of their use of over-thecounter medicines. Clin. Pediat. 21, 298-301, 1982.

10. Bush P. J. and Rabin D. L. Who's using nonprescribed medicines? Med. Care 14, 1014-1023, 1976.

11. National Analysts, Inc. A study of health practices and opinions. Public Health Service Publication No. PB-210 978, Government Printing Office, Washington, D.C. 1972.

12. Silverman M. and Lee P. R. Pills, Profits and Politics. University of California Press, Berkeley, 1974.

13. Crooks J. and Christopher L. J. Use and misuse of home medicines. In Self Medication (Edited by Anderson J. A. D.), pp. 31-38. MTP Press, Lancaster, 1979.

14. Cummings K. M., Becker $M$. H. and Maile $M$. E Bringing the models together: An empirical approach to combining variables used to explain health actions. J. behav. Med. 3, 123-145, 1980.

15. Becker M. H., Drachman R. H. asnd Kirscht J. P. Motivations as predictors of health behavior. Hlth Sert Rep. 87, 852-862, 1972.

16. Banks F. R. and Keller M. D. Symptom experience and health action. Med. Care 9, 498-502, 1971 .

17. Jones R. A., Wiese H. J., Moore R. W. and Haley J. V. On the perceived meaning of symptoms. Med. Care 19 , 710-717, 1981

18. Kim J. and Mueller C. W. Introduction to Factor Analysis. Sage Publications, Beverly Hills, 1978.

19. Kerlinger F. N. Foundations of Behavioral Research, 2nd edition. Holt, Rinehart \& Winston, New York, 1973.

20. Becker M. H., Drachman R. H. and Kirscht J. P. A new approach to explaining sick-role behavior in lowincome populations. Am. J. publ. Hlth 64, 205-216, 1974.

21. Becker M. H., Maiman L. A., Kirscht J. P., Haefner D. P. and Drachman R. H. The Health Belief Model and prediction of dietary compliance: a field experiment. J. Hith soc. Behav. 18, 348-366, 1977.

22. Green L. W. Status identity and preventive health behavior. Pacific Hlth Educ. Rep. 1, 115, 1970.

23. U.S. Bureau of Census. 1980 Census of Population and Housing: Census Tracts, Rochester, New York. U.S Government Printing Office, Washington, D.C., 1983.

24. Labovitz $S$. The assignment of numbers to rank order categories. Am. sociol. Rev. 35, 515-524, 1970.

25. Fleiss J. L. Statistical Methods for Rates and Proportions. Wiley, New York, 1973.

26. Andersen R., Kravitzs J, and Anderson O. W. (Eds) Equity in Health Services: Empirical Analyses in Social Policy. Ballinger, Cambridge. 1975.

27. Hershey J. C., Luft H. S. and Gianaris J. M. Making sense out of utilization data. Med. Care 13, 838-854, 1975.

28. Cummings K. M., Jette A. M., Brock B. M. and Haefner D. P. Psychosocial determinants of immunization behavior in a swine influenza campaign. $\mathrm{Med}$. Care 12, 639-649, 1979.

29. Kasl S. V. and Cobb S. Health behavior, illness behavior and sick-role behavior- $\mathrm{l}$. Health and health behavior. Archs envir. Hlth 12, 246-267, 1966.

30. Kasl S. V. and Cobb S. Health behavior, illness behavior and sick-role behavior-II. Sick-role behavior Archs envir. Hlth 12, 531-54l, 1966.

31. Zola I. K. Taking your medication: problem for doctor or patient. In Medication Compliance: A Beharioral Management Approach (Edited by Barofsky I.). Charles B. Slack, Thorof: re. N.J.. 1977. 
32. Report by an Ad-Hoc Working Group. Minimum information for sensible use of self-prescribed medi- cines: an international consensus. Lancet 2, 1017-1019. 1977.

\section{APPENDIX A}

Dependent Variables: Measures of Mother-Initiated Medication Behavior

Variable name and description
Number of different categories of
medications possessed (sum score of
4 items by categories, including
categories mentioned in items 1,2
and 4 not listed in item 3)

and 4 not listed in item 3)

Number of different categories of medications used (sum score of 4 items by categories, including categories mentioned in items 1,2 and 4 not listed in item 3 )

Number of types of appliances possessed

Number of types of appliances used
1. Medicines used last time mother gave index child medicine (open-ended item)

2. Medicines (non-prescription and left-over prescription), kept in house in case index child should get sick (open-ended item)

3. List of 19 categories of medicines kept in house in case index child should get sick [antacids, vitamins, internal decongestants, antibiotics, laxatives, analgesics, pain medicines, antidiarrheals, cough medicines, antihistamines, dermatologicals (anti-infectives; rash, antifungals, and topical anesthetics; and chafing), sleeping aids, tranquilizers, emetics, suppositories, enemas and antinauseants]

4. Any other medicines kept in house for index child (open-ended item)

1. Medicines used last time mother gave index child medicine (open-ended itcm)

2. Medicines kept in house for index child that are used in an average year (open-ended item)

3. List of 19 categories of medicines kept in house for index child that are used in an average year (same list as medications possessed)

4. Any other medicines kept in house for index child that are used in an average year (open-ended item)

1. List of 7 medical appliances kept in house for children (fever thermometer, vaporizer. ace bandage, scale, heating pad, enema bag and ice bag)

2. List of 7 medical appliances kept in house that are used for index child (same list as appliances possessed)
Number of different categories (excluding categories mentioned in itcm 1)

Number of different categories (excluding categories mentioned in items 1 and 2)

Number of different categories (excluding categories mentioned in items 1,2 and 3)

Number of different categories

Number of different categories (excluding categories mentioned in item 1)

Number of different categories (excluding categories mentioned in items 1 and 2)

Number of different categories (excluding categories

mentioned in items 1,2 and 3)

Number of different types

Number of different types 
APPENDIX B

Factor Loadings of Medication and Health Related Attitudinal Items on Each of Three Principal Factors

\begin{tabular}{|c|c|c|c|c|}
\hline Scale items & Variable name & $\begin{array}{l}\text { Factor } 1 \\
\text { (Propensity } \\
\text { to initiate } \\
\text { medication) }\end{array}$ & $\begin{array}{l}\text { Factor } 2 \\
\text { (Benefits } \\
\text { of OTCs) }\end{array}$ & $\begin{array}{c}\text { Factor } 3 \\
\text { (Frequency of } \\
\text { health } \\
\text { problems) }\end{array}$ \\
\hline $\begin{array}{l}\text { I usually save what is left over from a } \\
\text { prescription medicine just in case } \\
\text { (child) gets the same problem again* }\end{array}$ & $\begin{array}{l}\text { Saves Rx meds. for } \\
\text { (child) }\end{array}$ & 0.47 & -0.00 & 0.00 \\
\hline $\begin{array}{l}\text { I try to keep a variety of medicines at } \\
\text { home in case (child) gets sick and } \\
\text { needs them* }\end{array}$ & $\begin{array}{l}\text { Keeps meds. in } \\
\text { home for (child) }\end{array}$ & 0.71 & 0.24 & -0.08 \\
\hline $\begin{array}{l}\text { Most of (child's) illnesses can be } \\
\text { taken care of with over-the-counter } \\
\text { medicines* }\end{array}$ & $\begin{array}{l}\text { Benefit of OTCs for } \\
\text { (child's) illnesses }\end{array}$ & 0.04 & 0.60 & 0.08 \\
\hline $\begin{array}{l}\text { When I get sick. I find an over-the- } \\
\text { counter medicine often works just } \\
\text { as well for me as prescription } \\
\text { medicine* }\end{array}$ & $\begin{array}{l}\text { Benefits of OTCs for } \\
\text { mother's illnesses }\end{array}$ & 0.17 & 0.68 & 0.13 \\
\hline $\begin{array}{l}\text { I try to keep a variety of medicines } \\
\text { at home in case I get sick and } \\
\text { need them }\end{array}$ & $\begin{array}{l}\text { Keeps meds. in home } \\
\text { for self }\end{array}$ & 0.60 & 0.16 & -0.22 \\
\hline $\begin{array}{l}\text { How often would you say your family is } \\
\text { troubled with sickness? }{ }^{+}\end{array}$ & $\begin{array}{l}\text { Family troubled by } \\
\text { sickness }\end{array}$ & -0.08 & 0.08 & 0.70 \\
\hline $\begin{array}{l}\text { And how often would you say you are } \\
\text { troubled with sickness?t }\end{array}$ & $\begin{array}{l}\text { Mother troubled by } \\
\text { sickness }\end{array}$ & -0.13 & 0.10 & 0.72 \\
\hline Alpha coefficient & & 0.62 & 0.60 & 0.69 \\
\hline
\end{tabular}

Note: as there is no standardized method for determining the significance of factor loadings [18], loadings of 0.45 or higher are considered significant for purposes of this paper.

* Responses to statements were coded on a 5-point scale from $1=$ strongly agree to $5=$ strongly disagree.

$\dagger$ Responses to questions were coded on a 7 -point scale from $1=$ almost never to $7=$ very often. 